\title{
Comparison between Effect of McConnell Tape, Kinesiology Tape and Open Knee Brace in Treatment of Patellofemoral Pain
}

\author{
ENGY F. ADLY, M.Sc.*; NABIL M. ABDEL-AAL, Ph.D.*; ABEER A. EL YAMNY, Ph.D.* and \\ AHMED E.M. SHAHEEN, M.D.** \\ The Department of Physical Therapy for Basic Sciences*, Faculty of Physical Therapy, Cairo University, Giza, Egypt and \\ Department of Orthopedic Surgery**, Faculty of Medicine, Menofya University, Egypt
}

\begin{abstract}
Background: Patellofemoral Pain Syndrome (PFPS) is the most prevalent orthopedic condition among physically active adolescents and young adults. PFPS is reported to be between $15 \%$ and $25 \%$ in young adults. Women are affected about more than twice as often as men.
\end{abstract}

Aim of Study: Investigate the effect of Kinesiology taping, McConnell taping and Open knee brace beside the routine physical therapy in treatment of Patellofemoral pain syndrome (PFPS).

Material and Methods: Forty-eight patients (19 males, 29 Females) with unilateral PFPS randomly assigned equally into McConnell tape (MT) group, Kinesiology tape (KT) group, and Open knee brace group (KB). All subjects received interferential therapy, patellar mobilization, quadricepsstrengthening exercise and stretching exercise beside MT or KT or KB. The patients were evaluated by electrogoniometer for knee flexion active range of motion (FAROM), Kujula questionnaire for functional activities and Visual Analogue Scale (VAS) for pain assessment. The evaluation was applied before, after 3 weeks and after 6 weeks of intervention.

Results: There was no significant difference between the three groups in VAS, Kujula score and FAROM after three weeks of intervention $(p>0.05)$. After six weeks of intervention, there was a statistical significance in VAS and in Kujula score for MT group $(p<0.05)$. However, there was no statistically significant difference in FAROM between three groups. There was a statistically significant improvement in VAS, Kujula score and FAROM after three weeks as well as after six weeks of intervention in all groups $(p<0.0001)$.

Conclusion: Adding MT, KT or KB to physical therapy program might be effective in treatment patellofemoral pain, MT was more effective in improving pain and Kujula score, but not for FAROM, than other modalities.

Key Words: Patellofemoral pain syndrome - McConnell tape - Kinesiology tape - Open knee brace.

Correspondence to: Dr. Engy F. Adly, The Department of Physical Therapy for Basic Sciences, Faculty of Physical Therapy, Cairo University, Giza, Egypt

\section{Introduction}

PATELLOFEMORAL Pain Syndrome (PFPS) is a diffuse pain at the front of the knee or peripatellar pain, which is exacerbated by activities that load the patellofemoral joint [1]. It is the most prevalent orthopedic condition among physically active adolescents and young adults also contributing up to estimated $30 \%$ to $40 \%$ of all sports medicine visits. Patellar malalignment and abnormal patellar tracking are considering the main causes of PFPS [2,3]. Pain is most prominent when ascending or descending stairs, squatting, or sitting for prolonged periods with the knees flexed $[4,5]$ Women are affected about more than twice as often as men [6]

Several risk factors contributing to PFPS development; including quadriceps muscle weakness, patellar lateral retinaculum tightness, abnormal vastus medialis oblique (VMO)/vastus lateralis (VL) reflex timing, lower extremity anatomical anomalies, and altered hip/lower extremity kinematics [7]. Conservative methods are often used in the treatment of PFPS. However, there is no agreement on the most optimal treatment approach. The conservative treatment include physiotherapy modalities [8], strengthening exercises [9], stretching exercises [10] for the muscles around the knee, patellar brace [11], patellar taping [12], and feet orthotics [13].

Applying Kinesio taping to PFPS patients significantly reduces pain and increases muscle flexibility when compared with the control groups [14] The pain relief caused by facilitation of quadriceps muscle contraction. The increased muscle strength can provide dynamic patellar stability to maintain normal patellar tracking, thus reducing pain [15] 
However, some studies found that Kinesio tape has not effect or there was not significance difference between kinesio tape and other types of tapes or modalities [16,17].

The principle of McConnell taping is to restrict abnormal patella tracking, thus reducing joint friction and oppression of the injured tissue [18] The clinical evidence for the success of this intervention is still unclear. An insufficient number of randomized controlled trials, inconsistency of tape application techniques and variance in measurement the outcome variables limit the strength of clinical studies evidence [19].

Patellar bracing is commonly used in the management of PFPS. The primary goal of bracing is to centralize the patella within the trochlear groove, thus improving alignment and tracking [20]. It decreased both lateral tilt and translation of the patella during dynamic loading [21]. There is low evidence from heterogeneous trials using different types of knee orthoses (knee brace, sleeve and strap) that using a knee orthosis did not reduce knee pain or improve knee function in adults who were also performing an exercise programmed for treating PFPS [22].

The purpose of this study was to investigate the effect of adding Kinesio taping, McConnell taping, or open knee brace to the routine physical therapy program on functional activities, knee flexion active range of motion, and pain intensity for treatment of PFPS.

\section{Material and Methods}

Study design:

The study was A quasi-Experimental trial. Participants were recruited from Outpatient Physical Therapy Department of Hospitals of Ministry of Health and clinics of Health Insurance Organization. The clinical application of the study and the physical assessment of participants were conducted in the period between January 2019 and July 2019. Participants were invited to join the study and signed the written consent form prior to participation. The study was approved by the Ethical Committee for Human Research (Reference number P.T. REC/012/002136). The study was registered at Pan African Clinical Trials Registry (PACTR) with a registration number PACTR2019105 10244005.

\section{Participants:}

Forty-eight Subjects (19 males, 29 Females) were participated in this study. Their age ranged from 20 to 40 years old. All Patients were diagnosed with PFPS and referred to physical therapy by an orthopedist or general practitioner. The inclusion criteria were the age from 20 and 40 years, the body mass index (BMI) ranged between $23-31 \mathrm{Kg} /$ $\mathrm{m}^{2}$, the patients were diagnosed and referred by orthopedist as patellofemoral syndrome, the diagnosis were confirmed by knee $\mathrm{X}$-ray three views (anterior-posterior, Axial, sagittal view) or knee MRI, and unilateral anterior knee pain. The exclusion criteria were meniscal injury, osteoarthritis of Knee joint, previous patellar dislocation or subluxation, previous fractures with or without internal fixation in the knee region, any previous knee surgery, patellar tendon pathology, any lower limb deformities changing the global alignment, or referred pain from the spine. Participants were assigned randomly into three equal groups, $\mathrm{McCo}-$ nnell tape Group (MT), Kinesiology tape Group $(\mathrm{KT})$, and Open knee brace Group (KB).

\section{Sample size and randomization:}

A priori sample size has been calculated by Gpower 3.1.9.2 [F tests- MANOVA: Repeated measures, within-between interaction], with effect size equals 0.4 [15], alpha error probability was 0.05 , and the power was $80 \%$. The supposed sample size was 40 subjects and the number increased by $15 \%$ to be forty-six to consider the drop out. Forty-eight patients were divided randomly into three equal groups using a computer-generated block randomization with block size equal 4 and concealed allocation was done by the use of sealed opaque envelopes. All patients will sign a consent form before starting the study.

\section{Outcome measurements:}

All outcome measures were evaluated before starting the study, after 3 weeks and at the end of the study after 6 weeks. The assessor was blinded about the type of treatment.

Visual Analogue Scale (VAS) was used for determination of pain intensity. Subjects were instructed to rate their pain on a scale from 0 $100 \mathrm{~mm}$ with zero defined as no pain at all and $100 \mathrm{~mm}$ defined as "the worst possible pain" [23]

The Kujala Scale is a 13-item knee-specific self-report questionnaire. It documents response to six activities thought to be associated specifically with anterior knee pain syndrome (walking, running, jumping, climbing stairs, squatting, and sitting for prolonged periods with knees bent), as well as symptoms such as limp, inability to weight bear 
through the affected limb, swelling, abnormal patellar movement, muscle atrophy and limitation of knee flexion. The maximum score is 100 and lower scores indicate greater pain/disability [24].

The Flexion Active Range of Motion (FAROM) was measured by the electrogoniometer. The electreogoniometer placed on the lateral aspect of the knee and its fulcrum on the tibiofemoral joint and fitted to the knee by elastic straps. The assessment of ROM was in form of flexion arc where the starting of ROM of flexion from extreme active extension point, the patient can do it (zero point), to extreme active flexion point (reading measuring) without pain $[25,26]$.

\section{Intervention:}

All patients in the 3 groups did stretching exercises, strengthening exercises, Patellar mobilization [16], and interferential current therapy $[27,28]$ as described in Table (1). In the KT group, application of a 2-inch width I strip of kinesio tape split to a $\mathrm{Y}$ was used proximal to the superior patellar border. With the patient in a supine with knee fully extended position, the strip was applied starting approximately $10 \mathrm{~cm}$ below the anterior superior iliac spine (origin of rectus femoris) with an I base at zero tension as in Fig. (2A). An I strip was applied to the VMO (at an approximately 50-55 angle to the femur's long axis), its base starting at zero tension, and then lined to the patella at $50 \%$ tension [29] as in Fig. (2B). In MT group, taping was started at the mid lateral border, brought across the face of the patella, and secured to the medial border of the medial hamstring tendons while the patella was pulled in a medial direction. The medial soft tissues were brought over the medial femoral condyle toward the patella to obtain a more secure fixation as in Fig. (2C) [30]. Knee brace provided an external medially directed force, which may counteract lateral patella mal tracking. The patient wore it from long sitting and the knee were in extension. The patients fit the hole of brace on the patella boundaries. The patients wore the brace all day and remove it at sleeping as in Fig. (2D).

\section{Statistical analysis:}

Demographic data were conducted using mean and standard deviation. The Visual Analogue Scale (VAS), Kujula Questionnaire and Flexion Active Range of Motion (FAROM) for three groups conducted using mean and standard deviation. Twoway mixed model MANOVA, with the time within subject factor, were done to determine any differences between the mean change scores of each group regarding visual analogue scale, Kujula questionnaire and FAROM. The F-value was used based on Wilks' lambda. The alpha level was set at $\alpha=0.05$. Univariate ANOVAs (2-way mixed model) were performed with Bonferroni adjusted $p$-values to protect against the possibility of type I error.

\section{Results}

The participants flow throughout the study is shown in Fig. (1). The bio-demographic and clinical characteristics data of all patients at the baseline for the three groups are given in Table (2). The results showed no statistically significant differences between groups regarding age, weight, height, body mass index, VAS, Kujula questionnaire and $\operatorname{FAROM}(p>0.05)$.

Repeated measures multivariate analysis was conducted to assess the difference between patients in the McConnell tape group, kinesio tape group and Open Knee Brace group patients in the amount of change in their scores on the three outcome measures. No significant multivariate effects were found for the main effects of group, Wilks $\mathrm{A}=0.88$, $\mathrm{F}(6,86)=0.9, p=0.5, \eta 2=0.06$. However, there were significant multivariate effects for time, Wilks $\mathrm{A}=0.03, \mathrm{~F}_{(6,40)}=208.37, p<0.0001, \eta 2=0.97$, and the interaction between group and time, Wilks $\mathrm{A}=0.26, \mathrm{~F}_{(12,80)}=6.42, p<0.0001, \eta 2=0.49$. Univariate test reveal that significant change for VAS $\mathrm{F}(4,90)=5.08, \mathrm{p}=0.001, \eta 2=0.18$ and for Kujula score $\mathrm{F}(4,90)=28.54, p<0.001, \eta 2=0.55$ but, no significant change for FAROM F $(4,90)={ }^{2}, 79$ $p=0.07, \eta 2=0.11$.

Between-group comparison: There was no significant difference between the three groups in VAS, Kujula score and FAROM before as well as after three weeks of intervention $(p>0.05)$ as shown in Tables $(2,3)$. After six weeks of intervention, there was a significant decrease in VAS score and significant increase in Kujula score for MT group compared with other groups $(p<0.05)$, but there was no statistically significant difference in FAROM between the groups as shown in Table

Within-group comparison: There was a statistically significant improvement in VAS, Kujula score and FAROM after three weeks as well as after six weeks of intervention compared with that at the baseline in all groups $(p<0.0001)$ as in Table 
Table (1): The Physical Therapy intervention details which were used in the study.

\begin{tabular}{|c|c|}
\hline Intervention & Description \\
\hline Stretching exercises & $\begin{array}{l}\text { - (8-10 sets of } 10 \text { seconds hold): Quadriceps muscle stretches, Hamstring muscle } \\
\text { stretching, Gastrocnemius muscle stretching, tract stretching while standing. }\end{array}$ \\
\hline Strengthening exercises & $\begin{array}{l}\text { - Quadriceps muscle isometric contraction in sitting } 8-10 \text { sets of } 5 \text { seconds hold of } \\
\text { weak muscles (VMO muscle) around the patella to promote active medial stability } \\
\text { and involve patella wearing during patella wearing, Terminal knee extension ( } 0 \text { - } \\
\text { 30) in sitting } 3 \text { sets of } 10 \text { repetitions, Isometric hip abduction in sitting } 8-10 \text { sets } \\
\text { of } 5 \text { seconds hold, Straight leg extension in sitting ( } 3 \text { sets of } 10 \text { reps), Straight leg } \\
\text { extension with bridge exercise ( } 3 \text { sets of } 10 \text { reps)and dorsiflexed ankle ( } 3 \text { sets of } \\
10 \text { steps). }\end{array}$ \\
\hline Patellar mobilization & $\begin{array}{l}\text { - Subject was instructed to lie down in half lying position and his/her knees extended } \\
\text { then medial and lateral glide of the patella will be applied. }\end{array}$ \\
\hline Interferential current & $\begin{array}{l}\text { - Carrier frequency } 4000 \mathrm{~Hz} \text {, beat frequency } 100 \mathrm{~Hz} \text {, Quadripolar technique applied, } \\
\text { duration } 20 \text { min. }\end{array}$ \\
\hline
\end{tabular}

Table (2): Baseline demographic and clinical characteristics of subjects $(\mathrm{N}=48)$.

\begin{tabular}{|c|c|c|c|c|c|}
\hline Characteristics & $\begin{array}{l}\text { MT group } \\
\mathrm{n}=16\end{array}$ & $\underset{n=16}{\text { KT group }}$ & $\begin{array}{c}\mathrm{KB} \text { group } \\
\mathrm{n}=16\end{array}$ & F-value & $p$-value \\
\hline Age (years) & $30.12 \pm 6.05$ & $31.19 \pm 7.04$ & $9.87 \pm 6.26$ & 0.19 & 0.83 \\
\hline Weight (Kg) & $74.13 \pm 10.2$ & $75.18 \pm 10.19$ & $76.33 \pm 11.09$ & 0.18 & 0.84 \\
\hline Height $(\mathrm{cm})$ & $164.31 \pm 8.0$ & $162.81 \pm 9.17$ & $163 \pm 9.08$ & 0.14 & 0.87 \\
\hline $\mathrm{BMI}\left(\mathrm{Kg} / \mathrm{m}^{2}\right)$ & $27.39 \pm 2.3$ & $28.23 \pm 1.78$ & $28.85 \pm 1.34$ & 2.51 & 0.092 \\
\hline VAS score pre & $74.4 \pm 9.6$ & $70.6 \pm 10.6$ & $73.1 \pm 13$ & 4.6 & 6.3 \\
\hline Kujula score Pre & $65.5 \pm 6.59$ & $71.38 \pm 8.45$ & $70.56 \pm 8.01$ & 2.72 & 0.77 \\
\hline FAROM $\left({ }^{\circ}\right)$ pre & $95.25 \pm 6.04$ & $96.56 \pm 6.65$ & $98.25 \pm 5.13$ & 1.01 & 0.37 \\
\hline \multicolumn{6}{|l|}{ Gender: } \\
\hline Male n (\%) & $6(37.5 \%)$ & $7(43.75 \%)$ & $6(37.5 \%)$ & $X^{2}=0.17$ & 0.91 \\
\hline Female n (\%) & $10(62.5 \%)$ & $9(56.25 \%)$ & $10(62.5 \%)$ & & \\
\hline \multicolumn{6}{|l|}{ Affected Side: } \\
\hline Right n (\%) & $7(44 \%)$ & $10(63 \%)$ & $10(63 \%)$ & $X^{2}=1.52$ & 0.46 \\
\hline Left n $(\%)$ & $9(56 \%)$ & $6(37 \%)$ & $6(37 \%)$ & & \\
\hline $\begin{array}{l}\text { MT : McConnell Tape. } \\
\text { KT : Kinesiotape. } \\
\text { KB : Open Knee Brace. } \\
\text { BMI : Body mass index. }\end{array}$ & $p-$ & $\begin{array}{l}\text { ual analogue scal } \\
\text { Flexion active } r \\
\text { nean } \pm \text { SD, exce } \\
0.05 \text { indicates sta }\end{array}$ & $\begin{array}{l}\text { motion. } \\
\text { er which are ce } \\
\text { significance. }\end{array}$ & & \\
\hline
\end{tabular}

Table (3): Pairwise comparison between three groups for Outcome Data of VAS, Kujula score and FAROM after 3 weeks and post treatment.

\begin{tabular}{|c|c|c|c|c|c|c|c|}
\hline \multirow{2}{*}{ Characteristics } & \multicolumn{2}{|c|}{ MT versus KT } & \multicolumn{2}{|c|}{ MT versus KB } & \multicolumn{2}{|c|}{$\mathrm{KT}$ versus KB } & \multirow{2}{*}{$\frac{\text { Partial Eta }}{\text { Square }}$} \\
\hline & MD (95\% CI) & $p$-value & MD (95\% CI) & $p$-value & $\mathrm{MD}(95 \% \mathrm{CI})$ & $p$-value & \\
\hline \multicolumn{8}{|l|}{ VAS: } \\
\hline 3 weeks & $-3.7(-14.6,7.1)$ & 0.99 & $-9.3(-20.2,14.4)$ & 0.11 & $-5.6(-16.4,5.2)$ & 0.61 & 0.09 \\
\hline 6 weeks & $-10.6(-20.2,-1.1)$ & 0.025 & $-11.3(-20.8,-1.7)$ & 0.016 & $-0.6(-10.2,8.9)$ & 0.99 & 0.19 \\
\hline \multicolumn{8}{|l|}{ Kujula: } \\
\hline 3 weeks & $-1.31(-7.5,4.9)$ & 0.99 & $1.3(-4.9,7.5)$ & 0.99 & $2.63(-3.6,8.8)$ & 0.89 & 0.02 \\
\hline 6 weeks & $6.37(0.91,11.84)$ & 0.017 & $8.19(2.72,13.66)$ & 0.002 & $1.81(-3.66,7.28)$ & 0.99 & 0.25 \\
\hline \multicolumn{8}{|l|}{ FAROM (deg.): } \\
\hline 3 weeks & $1.31(-4.97,7.6)$ & 0.99 & $-0.31(-6.6,5.97)$ & 0.99 & $-1.62(-7.91,4.66)$ & 0.99 & 0.01 \\
\hline 6 weeks & $3.38(-1.31,8.07)$ & 0.24 & $4.5(-0.19,9.19)$ & 0.06 & $1.13(-3.57,5.82)$ & 0.99 & 0.12 \\
\hline
\end{tabular}

VAS: Visual Analogue Scale.

FAROM: Flexion Active Range of Motion.

Deg.: Degrees.

$p$ : Probability value.
CI : Confidence interval.

MD: Mean Difference.

$p$-Value $<0.05$ indicates statistical significance. 
Table (4): Comparison between pre and post treatment Outcome Data for VAS, Kujula score and FAROM all groups.

\begin{tabular}{|c|c|c|c|c|c|c|}
\hline \multirow{2}{*}{ Characteristics } & \multicolumn{2}{|c|}{ Group MT $(n=16)$} & \multicolumn{2}{|c|}{ Group KT (n=16) } & \multicolumn{2}{|c|}{ Group KB $(n=16)$} \\
\hline & $\mathrm{MD}(95 \% \mathrm{CI})$ & $p$-value & $\mathrm{MD}(95 \% \mathrm{CI})$ & $p$-value & $\mathrm{MD}(95 \% \mathrm{CI})$ & $p$-value \\
\hline \multicolumn{7}{|l|}{$V A S:$} \\
\hline $\begin{array}{l}\text { Change from baseline } \\
\text { to } 3 \text { weeks }\end{array}$ & $-25(-31.5,-18.5)$ & $<0.0001$ & $-17.5(-24,-11)$ & $<0.0001$ & $-14.4(-20.9,-7.9)$ & $<0.0001$ \\
\hline $\begin{array}{l}\text { Change from baseline } \\
\text { to } 6 \text { weeks }\end{array}$ & $-41.2(-48,-34.5)$ & $<0.0001$ & $-26.9(-33.6,-20.1)$ & $<0.0001$ & $-28.8(-35.5,-22)$ & $<0.0001$ \\
\hline \multicolumn{7}{|l|}{ Kujula: } \\
\hline $\begin{array}{l}\text { Change from baseline } \\
\text { to } 3 \text { weeks }\end{array}$ & $10.13(7.66,12.59)$ & $<0.0001$ & $5.56(3.1,8.03)$ & $<0.0001$ & $3.75(1.28,6.22)$ & 0.001 \\
\hline $\begin{array}{l}\text { Change from baseline } \\
\text { to } 6 \text { weeks }\end{array}$ & $24.13(21.52,26.73)$ & $<0.0001$ & $11.88(9.27,14.48)$ & $<0.0001$ & $10.88(8.27,13.48)$ & $<0.0001$ \\
\hline \multicolumn{7}{|l|}{ Flex (deg.): } \\
\hline $\begin{array}{l}\text { Change from baseline } \\
\text { to } 3 \text { weeks }\end{array}$ & $16.25(11.96,20.54)$ & $<0.0001$ & $13.63(9.34,17.91)$ & $<0.0001$ & $13.56(9.28,17.85)$ & $<0.0001$ \\
\hline $\begin{array}{l}\text { Change from baseline } \\
\text { to } 6 \text { weeks }\end{array}$ & $29.69(25.26,34.11)$ & $<0.0001$ & $25(20.58,29.43)$ & $<0.0001$ & $22.19(17.76,26.61)$ & $<0.0001$ \\
\hline
\end{tabular}

VAS: Visual Analogue Scale; FAROM: Flexion Active Range of Motion; Deg.: Degrees; $p$ : Probability value; CI: Confidence interval; MD: Mean Difference; $p$-Value $<0.05$ indicates statistical significance.

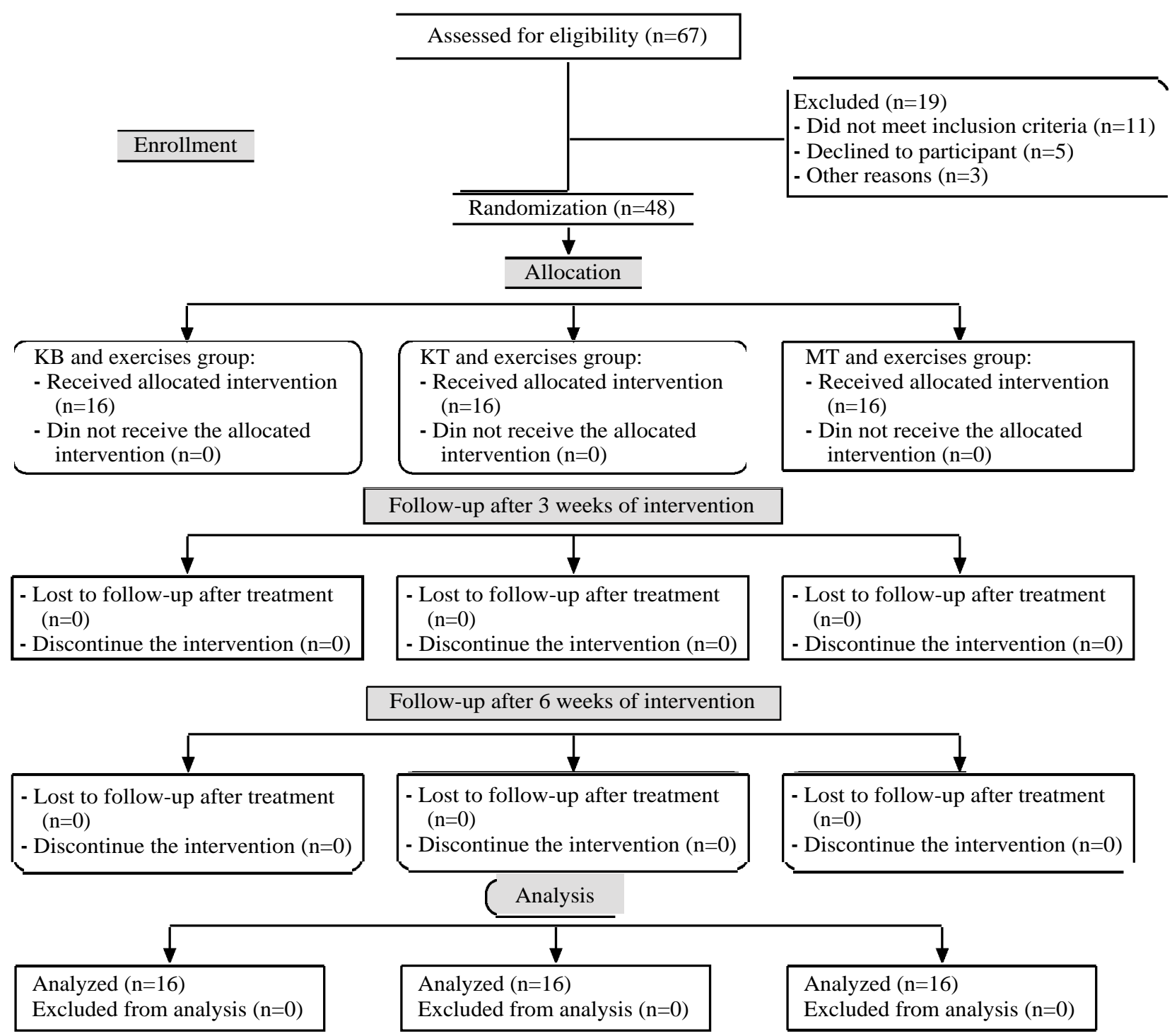

Fig. (1): Flow diagram showing the progress of subjects at each stage of the clinical trial. 
(A)

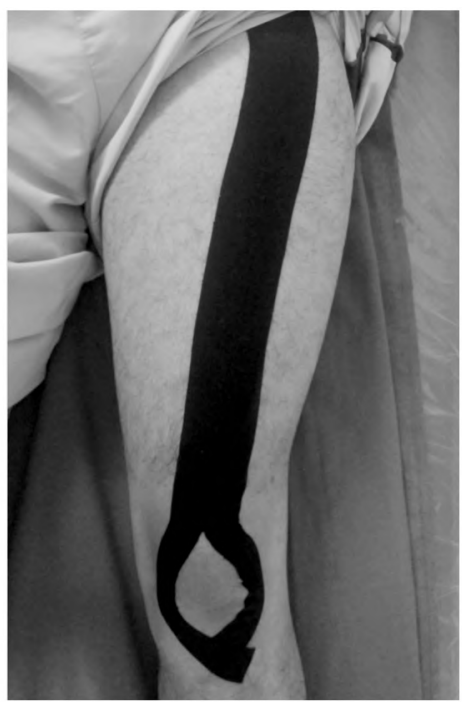

(C)

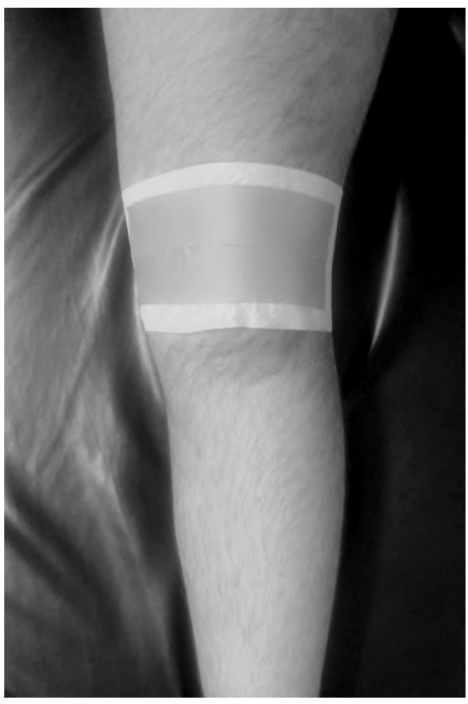

(B)

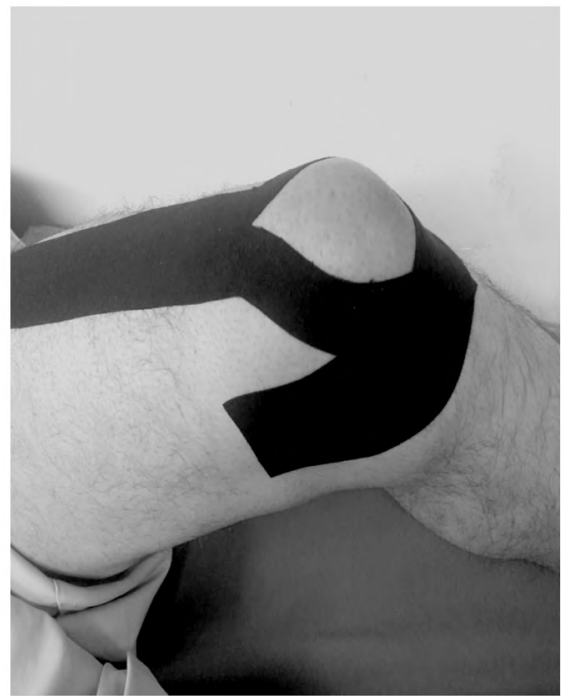

(D)

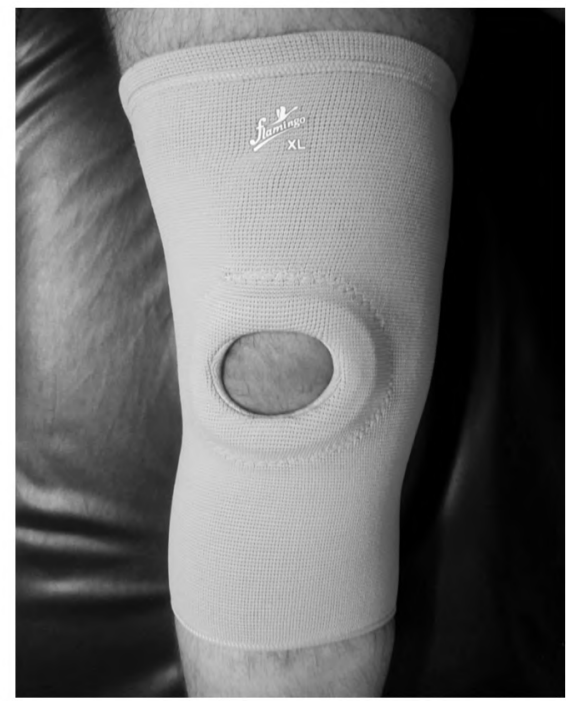

Fig. (2): (A,B): Kinesiology tape application. (C) McConnell Application. (D) Open Knee Brace.

\section{Discussion}

The purpose of the study was to investigate the effect of MT, KT and KB beside physical therapy on the PFPS. The results showing improving in VAS score, Kujula score and FAROM for three groups. There was a significant decrease in VAS score and significant increase in Kujula score for MT group compared with other groups $(p<0.05)$, but there was no statistically significant difference in FAROM between the groups. No significance differences were found between KT and KB groups for all outcome measurements.

The McConnell taping technique utilizes a rigid and highly adhesive tape that is structurally supportive and, when applied, it has been suggested to alter lateral tilt, lateral displacement, and patella Alta [31]. McConnell taping has medial glide technique that is proposed to have three effects: Patellar glide, patellar tilt, and patellar rotation $[32,33]$ McConnell taping enhanced the efficiency and activation of vastus medial obliques [34] and decrease activity of vastus lateralis [35]. It also facilitated the force generated from quadriceps in both concentric and eccentric contractions [36].

McConnell taping had significant effect on knee proprioception and stimulate cutaneous mechanoreceptors therefore allowing more sensory signals to be carried to central nervous system for more integration [37-39] decreasing patellofemoral joint reaction force [40]. These mechanisms explain how MT works to treat the patients with PFPS. McConnell taping was used successfully in treatment of PFPS [41,42]. Whittingham et al. [43] found decreasing in pain level and improving in functional activities after four weeks of combination of patellar taping and exercises. 
Begum and his colleagues used MT with Exercises for females with PFPS there was decreasing in pain score, improving in functional activities and increasing Knee flexion Rom of Motion [44] Callaghan and Selfe assessed the taping effect on pain and function in PFPS. They found no statistically or clinically significant difference between taping and non-taping in pain at the end of the treatment programs. The data of outcomes measuring functional activities gave contradictory results [45]. Leibbrandt and Louw concluded that the evidence was insufficient to justify routine use of the MT technique in the treatment of anterior knee pain [46].

Ho et al., evaluated the effect of MT and KT on patellofemoral joint alignment and contact area in weight bearing activities by using MRI. The results did not reveal any significant effect for MT or KT in medial patellar correction or patellar tilt angle. The pain reduced after KT application than MT application [47]. These results opposed the results of current study which demonstrated superiority MT on KB in VAS and opposed the theory that MT providing medial correction for patellar position. This study using MRI evaluation but the sample size was small and all subjects were females which make a bias and make the results exclusive to the females.

Kinesio tape was had statistically significance in immediate pain improving and single leg hop function in patients with PFPS when compared with sham application [48]. Campolo compared between the effect of MT and KT on functional activities in anterior knee pain [18]. Kumar also compared the immediate effect of MT and KT on functional activities in PFPS [49]. Both studies founded that KT significant decrease the pain during functional activities but there was no significant difference with comparing to McConnell tape. The results disagree with the results of current study which provide MT had a significant effect in pain and functions than KT. The contradiction may be due to both studies examined the efficacy of taps during functional activities without any treatment program for a specific period of time.

Kuru conducted a comparative study between KT and electro stimulation beside strengthening and stretching exercises for 6 weeks. The results showed decreasing pain, improving functional activities and increasing range of motion but there was not significant difference between the two modalities [17].
Draper et al have demonstrated by MRI evaluation that the knee brace applies a medially directed force on the patella can reduce patellar lateralization and tilt in women with PFPS significantly better than a bandage [50]. Powers et al., conducted a study for orthosis that applied a medially directed force on the patella in PFPS patients and there was decreasing in pain level and increased activation of the quadriceps [51].

Arazpour et al., conducted a study for The effect of patellofemoral bracing on walking in individuals with patellofemoral pain syndrome KB eight hours daily resulted in decreased pain on VAS after six weeks, increase Knee flexion angle, speed of walking and step length in patients with PFPS and the subjects did not received physical therapy beside KB [52] . Van Linschoten et al., observed at rest and with activity the pain was decreased and improving in functional activity after 3 months in the patients who using brace and had greater improvement than non-braced patients [53]. Knee brace decreasing VAS and improving Kujula score in PFPS patients than on braced patients [54].

Power et al., evaluated the Influence of Patellofemoral Bracing on Pain, Knee Extensor Torque and gait function in Females with Patellofemoral pain. There was not significant difference in pain, torque and gait function in immediate effect of patello femoral bracing. These results disagree with the current study in pain and in functions (gait) may be due to the design of the study (crosssectional study), Small sample size (16 subjects) and wide age range (14-46y) [55]

Victor et al., evaluate the Effectiveness of patellar bracing for treatment of patellofemoral pain syndrome they found that adding KB to the home exercises did not improve the symptoms of PFPS in short time. The study using pain score evaluation related to sport activities not functional activities of daily living. KB protocol was not clear how long was wearied per day which may interfere with the efficiency of KB in the treatment [56].

\section{Limitations:}

Limitations of the current study included that there was not control group with routine physical therapy Therefore, the findings of the current study need to be examined with control group for comparison and demonstration the clinical effect of taping techniques and knee brace. The study also limited by small sample size so it is recommended further study with larger sample size. The relative short period of the study without long term follow up consider a limitation for the current study. 
Further studies need to increase the period of treatment with follow-up for detecting the clinical efficiency and long term effect for taping techniques and knee brace.

\section{Conclusion:}

Adding MT, KT or KB to physical therapy program might be more effective in reducing patellofemoral pain, improving Kujula score and increase knee FAROM. The use of MT was more effective in improving pain intensity and Kujula score, but not for FAROM, than the KT and KB.

\section{References}

1- CROSSLEY K., COWAN S.M., BENNELL K.L. and McCONNELL J.: Patellar taping: Is clinical success supported by scientific evidence? Man Ther., 5 (3): 142$150,2000$.

2- BIZZINI M., CHILDS J.D., PIVA S.R. and DELITTO A.: Systematic review of the quality of randomized controlled trials for patellofemoral pain syndrome. J. Orthop. Sports Phys. Ther., 33: 4-20, 2003.

3- HOUGHTON K.M.: Review for the generalist: Evaluation of anterior knee pain. Pediatr. Rheumatol., 5: 8. doi: 10.1186/1546-0096-5-8, 2007.

4- KIM H. and CHANG H.S.: Comparison of the VMO/VL EMG ratio and onset timing of VMO relative to VL in subjects with and without patellofemoral pain syndrome. J. Phys. Ther. Sci., 24 (12): 1315-1317, 2012.

5- LANKHORST N.E., BIERMA-ZEINSTRA S.M. and VAN MIDDELKOOP M.: Risk factors for patellofemoral pain syndrome: A systematic review. J. Orthop. Sports Phys. Ther., 42 (2): 81-94, 2012.

6- BOLING M., PADUA D., MARSHALL S., GUSKIEWICZ K., PYNE S. and BEUTLER A.: Gender differences in the incidence and prevalence of patellofemoral pain syndrome. Scand J. Med. Sci. Sports, 20 (5): 725-730, 2010.

7- FULKERSON J.: Disorders of the Patellofemoral Joint. 4th ed. Baltimore, MD: Williams \& Wilkins, p 43-52, 2004.

8- SERVODIO I.C., CADOSSI M., SAMBRI A., GROSSO E., CORRADO B. and SERVODIO I.F.: Is there a role of pulsed electromagnetic fields in management of patellofemoral pain syndrome? Randomized controlled study at one year follow-up. Bio Electromagnetics, 37 (2): 81$8,2016$.

9- AL HAKIM W., KUMAR P., KHAN W. and JOHNSTON D.: The Non - Operative treatment of Anterior Knee Pain, Open Orthopedic Journal, 6: 320-329, 2012.

10- CLARK D.I., DOWNING N., MITCHELL J., COULSON L., SYZPRYT E.P. and DOHERTY M.: Physiotherapy for anterior knee pain: A randomized controlled trial. Ann. Rheum. Dis., 59: 700-704, 2000.

11- SISK D. and FREDERICSON M.: Taping, Bracing, and Injection Treatment for Patellofemoral Pain and Patellar Tendinopathy. Curr. Rev. Musculoskelet Med., 13 (4): 537-544, 2020.
12- WARDEN S.J., HINMAN R.S., WATSON M.A.Jr., AVIN K.G., BIALOCERKOWSKI A.E. and CROSSLEY K.M. Patellar taping and bracing for the treatment of chronic knee pain: A systematic review and meta-analysis. Arthritis Rheum., 15; 59 (1): 73-83, 2008.

13- BOLGLA L.A. and BOLING M.C.: An update for the conservative management of patellofemoral pain syndrome: A systematic review of the literature from 2000 to 2010. Int. J. Sports Phys. Ther., 6 (2): 112-25, 2011.

14- AKBAS E., ATAY A.O. and UKSEL I.Y.: The effects of additional kinesio taping over exercise in the treatment of patellofemoral pain syndrome, Acta Orthopaedicae Traumatologica Turcica., 45 (5): 335-341, 2011.

15- FREEDMAN S., BRODY L.T., ROSENTHAL M. and WISE C.J.: Short-Term Effects of Patellar Kinesio Taping on Pain and Hop Function in Patients With Patellofemoral Pain Syndrome, Sport Health, 6 (4): 294-300, 2014.

16- LÓPEZ B.A. and MARBÁN R.M.: Kinesio Taping and Patellofemoral Pain Syndrome: A Systematic Review. Central European Journal of Sport Sciences and Medicine, 9 (1): 47-54, 2015.

17- KURU T., YALIMAN A. and DERELI E.E.: Comparison of efficiency of Kinesio taping and electrical stimulation in patients with patellofemoral pain syndrome. Acta Orthopaedicaet Traumatologica Turcica., 46 (5): 385-392, 2012.

18- CAMPOLO M., BABU J., DMOCHOWSKA K., SCARIAH S. and VARUGHESE J.: A comparison of two taping techniques (kinesio and mcconnell) and their effect on anterior knee pain during functional activities, International Journal of Sports Physical Therapy, 8 (2): 105-110, 2013.

19-AMINAKA N. and GRIBBLE A.P.: A Systematic Review of the Effects of Therapeutic Taping on Patellofemoral Pain Syndrome. J. Athl Train, 40 (4): 341-351, 2005.

20- POWER C.M., WARD S.R., CHEN Y.J., CHAN L.D. and TERK M.R.: The Effect of Bracing on Patellofemoral Joint Stress During Free and Fast Walking, The American Journal of Sports Medicine, 32 (1): 224-231, 2004.

21- DRAPER C.E., BESIER T.F., SANTOS J.M., et al.: Using real-time MRI to quantify altered joint kinematics in subjects with patellofemoral pain and to evaluate the effects of a patellar brace or sleeve on joint motion. J. Orthop. Res., 27 (5): 571-577, 2009.

22- SMITH T.O., DREW B.T., MEEK T.H. and CLARK A.B.: Knee orthoses for treating patellofemoral pain syndrome. Cochrane Database of Systematic Review, Issue 12. Art. No.CD010513, 2015.

23- HAWKER G.A., MIAN S., KENDZERSKA T. and FRENCH M.: Measures of Adult Pain, Arthritis Care \& Research, 63 (11): S240-S252, 2011.

24- ALSHEHRI A., LOHMAN E., DAHER N.S., BAHIJRI K., ALGHAMDI A., ALTORAIRI N., ARNOS A. and MATAR A.: Cross-Cultural Adaptation and Psychometric Properties Testing of the Arabic Anterior Knee Pain Scale. Med. Sci. Monit., 23: 1559-1582. https://doi.org/ 10.12659/msm.901264, 2017.

25- CLELAND JOSHUA: Orthopaedic Clinical examinations, An Evidence- Based Approach for Physical Therapy. 1 st ed, Carlstadt, NJ: Icon Learning Systems, p 287, 2005. 
26- BROSSEAU L., BALMER S., TOUSIGNANT M., O'SULLIVAN J.P., GOUDREAULT C., GOUDREAULT M. and GRINGRAS S.: Intra- and Intertester Reliability and Criterion Validity of the Parallelogram and Universal Goniometers for Measuring Maximum Active Knee Flexion and Extension of Patients with Knee Restrictions. Arch. Phys. Med. Rehabil., 82 (3): 396-402, 2001.

27- BELLEW J.W., MICHLOVITZ S.L. and NOLAN T.P.: Modalities for Therapeutic Intervention, 6 th ed, F. A Davis Company, p 275-278, 2016.

28- ADEDOYIN R., OLAOGUN M. and FAGBEJA O.: Effect of Interferential Current Stimulation in Management of Osteo-arthritic Knee Pain. Physiotherapy, 88 (8): $493-$ 499, 2002.

29- CHANG W., CHEN F., LEE C., LIN H. and LAI P. Effects of Kinesio Taping versus McConnell Taping for Patellofemoral Pain Syndrome: A Systematic Review and Meta-Analysis, Evid Based Complement Alternat Med., 471208, 2015.

30- MAXEY L. and MAGNUSSON J.: Rehabilitation for the Postsurgical Orthopedic Patient. 3 rd ed ELSEVIER MOSBY, p 428, 2013

31- YUHO K., EPSTEIN R., GARCIA R., RILEY N., PING LEE S. and TURNER C.: Effects of Patellofemoral Taping on Patellofemoral Joint Alignment and Contact Area During Weight Bearing. Journal of orthopaedic \& sports physical therapy, 47 (2): 115-123, 2017.

32- CALLAGHAN M.J., SELFE J., BAGLEY P.J. and OLDHAM J.A.: The effects of patellar taping on knee joint proprioception. Journal of Athletic Training, 37 (1): 1924, 2002.

33- COWAN S.M., BENNELL K.L., CROSSLEY K.M., HODGES P.W. and McCONNELL J.: Physical therapy alters recruitment of the vasti in patellofemoral pain syndrome. Medicine and Science in Sports and Exercise, 34 (12): 1879-1885, 2002.

34- KEET J., GAY J., HARELY Y. and LAMBERT M.I.: The Effect of Medial Patellar taping on Pain, Strength and Neuromuscular Recruitment in Subjects With and Without Patellofemoral Pain. Physiotherapy, 93 (1): 45-52, 2007.

35- AMINAKA N. and GRIBBLE P.A.: "Patellar taping, patellofemoral pain syndrome, lower extremity kinematics, and dynamic postural control," Journal of Athletic Training, 43 (1): 21-28, 2008.

36- HERRINGTON L.: The effect of patellar taping on quadriceps peak torque and perceived pain: A preliminary study. Physic Thera Sport, 2 (1): 23-28, 2001.

37- LAN T.Y., LIN W.P., JIANG C.C. and CHIANG H.: Immediate Effect and Predictors of Effectiveness of Taping for Patellofemoral Pain Syndrome: A Prospective Cohort Study. American Journal of Sports Medicine, 38; (8): 1626-1630, 2010

38- DERASARI A., BRINDLE T.J., ALTER K.E. and SHEEHAN F.T.: McConnell Taping Shifts the Patella Inferiorly in Patients With Patellofemoral Pain: A Dynamic Magnetic Resonance Imaging Study. Journal of Physical Therapy, 90 (3): 411-419, 2010

39- CALLAGHAN M.J., SELFE J., McHENRY A. and OLDHAM J.A.: Effects of Patellar taping on knee joint prop- rioception in patients with patellofemoral pain syndrome. Manual Therapy, 13 (3): 192-199, 2008.

40- MOSTAMAND J., BADER D.L. and HUDSON Z.: The effect of patellar taping on joint reaction forces during squatting in subjects with patellofemoral pain syndrome (PFPS), Journal of Bodywork and Movement Therapies, 14; (4): 375-381, 2010.

41- CROSSLEY K., BENNELL K., GREEN S., COWAN S. and McCONNELL J.: Physical therapy for patellofemoral pain: A randomized, double-blinded, placebo-controlled trial, The American Journal of Sports Medicine, 30 (6) 857-865, 2002.

42- McCONNELL J.: Management of patellofemoral problems. Man Ther., 1 (2): 60-66, 1996.

43- WHITTINGHAM M., PALMER S. and MACMILLAN F.: Effects of Taping on Pain and Function in Patellofemoral Pain Syndrome: A Randomized Controlled Trial. Journal of Orthopaedic and Sports Physical Therapy, 34 (9): 504-510, 2004

44- BEGUM R., TASSADAQ N., AHMAD S., AJAS W.Q., JAVED S. and MURAD S.: Effects of McConnell Taping Combined with Strengthening Exercises of Vastus Medialis Oblique Females with Patellofemoral Pain Syndrome Pak Med. Assoc., 70 (4): 3QW, 2020.

45- CALLAGHAN M.J. and SELFE J.: Patellar taping for patellofemoral pain syndrome in adults. Cochrane Database Syst. Rev., 4: CD006717, 2012.

46- LEIBBRANDT D.C. and LOUW Q.A.: The use of McConnell taping to correct abnormal biomechanics and muscle activation patterns in subjects with anterior knee pain: A systematic review, J. Phys. Ther. Sci., 27 (7): 2395-2404, 2015

47- HO-K.Y., EPSTEIN GARCIA R. and RILEY N.: Effect of Patellofemoral taping on Patellofemoral Joint Alignment and Contact area during Weight Bearing. JOSPT, 47 (2): 115-123, 2017.

48- FREEDMAN S.R., THEIN L.B., ROSENTHAL M. and WISE J.C.: Short term effects of patellar kinesio taping on pain and Hop Function in Patients with Patellofemoral Pain Syndrome. Sport Health, 6 (4): 294-300, 2014.

49- KUMAR S.N., BABU V.K., AYYAPPAN V.R. and RAGESH S.S.: The immediate effect of Kinesio versus McConnell taping in patellofemoral pain during functional activities. Comparative study. Int. J. Physiother., 2 (6) 1077-1084, 2015

50- DRAPER C.E., BESIER T.F., SANTOS J.M., JENNINGS F., FREDERICSON M., GOLD G.E., BEAUPRE G.S. and DELP S.L.: Using real-time MRI to quantify altered joint kinematics in subjects with patellofemoral pain and to evaluate the effects of a patellar brace or sleeve on joint motion. J. Orthop. Res., 27 (5): 571-577, 2009.

51- POWERS C.M., WARD S.R., CHEN Y.J., CHAN L.D. and TERK M.R.: Effect of bracing on patellofemoral joint stress while ascending and descending stairs. Clin. J. Sport Med., 14 (4): 206-214, 2004.

52- ARAZPOUR M., NOTARKI T.T., SALIMI A., BANI M.A., NABAVI H. and HUTCHINS S.W.: The Effect of Patellofemoral Bracing on Walking in Individuals with Patellofemoral Pain Syndrome. Prosthet Ortho. Int., 37 (6): 465-470, 2013 
53- VAN LINSCHOTEN R., VAN MIDDEL KOOP M., BERGER M.Y., HEINTJES E.M., VERHAAR J.A., WILLEMSEN S.P., KOES B.W. and BIERMA-ZEINSTRA S.M.: Supervised Exercises Therapy Versus Usual Care for Patellofemoral Pain Syndrome: An open Label Randomized Controlled Trial. BMJ, 20: 339-346, 2009.

54- UBOLDI F.M., FERRUA P., TRADATI D., ZEDDE P., RICHARDS J., MANUNTA A. and BERRUTO M.: Use of an Elastomeric Knee Brace in Patellofemoral Pain Syndrome: Short-Term Results, Joints, 6 (2): 85-89, 2018.
55- POWER C.M., DOUBLE DAY K.L. and ESCUDERO C.: Influence of Patellofemoral Bracing on Pain, Knee Extensor Torque and gait function $n$ Females with Patellofemoral pain. Physiother Theory Pract, 24 (3): 143-150, 2008.

56- LUN V.L., PRESTON W.J., WILLEN M. and TERRI Y.: Effectiveness of Patellar Bracing for Treatment of Patellofemoral syndrome. Clinical J. of Sport Medicine, 15 (4): 233-240, 2005.

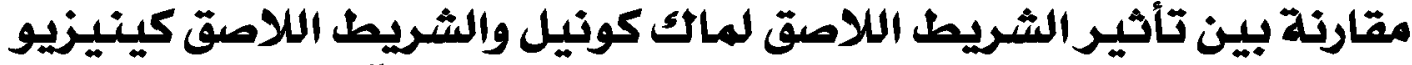

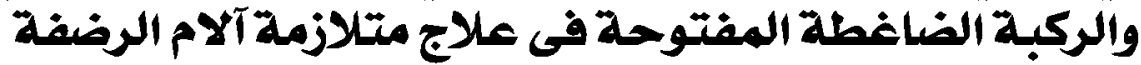

كانت الدراسة تهدف إلى مقارنة بين تأثير الشريط اللاصق الماك كونيل والشريط اللا صق الكينيزيو والركبة الضاغطة المفتوحة بجانب

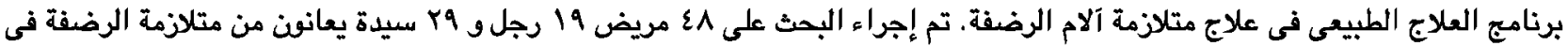

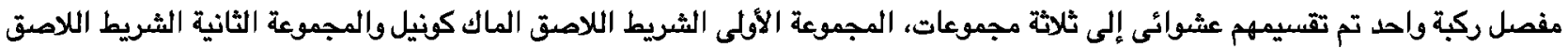

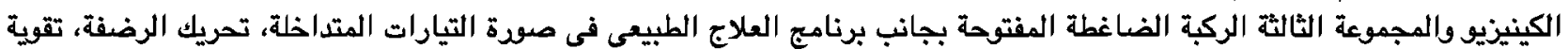
العضلة الرباعية الأمامية، وتمرينات الاطالة للعضلات.

تم تقييم المرضى بجهاز مقياس درجات الأكترونى لمعرفة مدى حركة ثنى الركبة بدف ألم، وإستييان الكوجالا لمعرفة مدى تأثر الانثطة

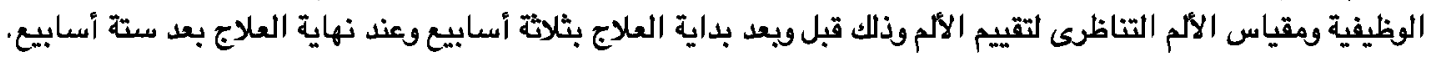

وفقاً للنتائج تبين أنه لا يوجد فرق ذات دلالة إحصائية بين الثالاثة مجموعات فى قياس الألم ومجموع نقاط إستبيان الكوجالا ومدى الحركة

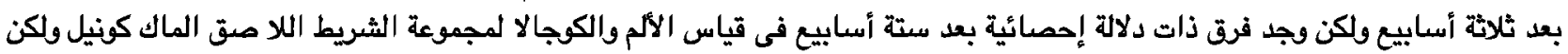

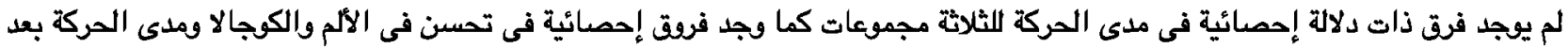

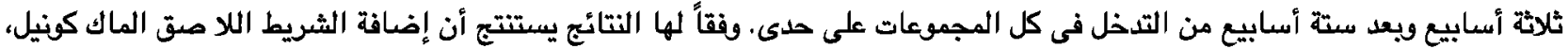

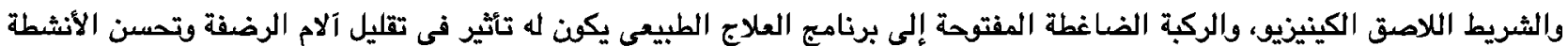
الوظيفية وزيادة مدى الحركة، مع أفضلية لمجموعة الشريط اللاهق الماكية كونئ الفيل في التقليل من مقدار الألم وتحسين الأنشطة الوظيفية. 